\title{
Recursos fílmicos e a prática pedagógica: um estudo sobre a visão de licenciandos sobre a sua utilização na educação básica
}

O processo de ensino-aprendizagem nunca precisou tanto ser inovado, o cinema tem papel fundamental no ensino na atualidade, trata-se de um recurso audiovisual muito utilizado em disciplinas teóricas e práticas. Este estudo tem como objetivo discutir sobre a importância da utilização de filmes em sala de aula e como esse recurso pedagógico, aplicado de maneira correta e coerente pelo professor, pode despertar no aluno o interesse pelo conhecimento. E apresenta dados em relação ao olhar dos discentes da graduação, acerca da utilização dessa ferramenta em sala de aula. Dos 19 discentes que responderam ao formulário,

18 afirmaram que utilizarão filmes em salas de aula e concordam que este recurso é fiel em transmitir o saber para os alunos. De maneira correta os meios audiovisuais atraem e incitam os alunos tornando-os sujeitos históricos.

Palavras-chave: Didática fílmica; Recursos; Ensino-aprendizagem; Filme; Educação.

\section{Film resources and pedagogical practice: a study on the perspective of undergraduates on their use in basic education}

The teaching-learning process has never needed so much to be innovated, cinema has a fundamental role in education today, it is an audiovisual resource widely used in theoretical and practical disciplines. This study aims to discuss the importance of using movies in the classroom and how this pedagogical resource, applied correctly and coherently by the teacher, can arouse interest in knowledge in the student. And present data in relation to the view of undergraduate students about the use of this tool in the classroom. Of the 19 students who responded to the form, 18 stated that they will use films in classrooms and agree that this resource is faithful in transmitting knowledge to students. Correctly, audiovisual media attract and incite students, making them historical subjects.

Keywords: Film didactics; Resources; Teaching-learning; Students; Education.

Topic: Ensinos Multidisciplinares

Reviewed anonymously in the process of blind peer
Received: 19/04/2021

Approved: 20/07/2021
Adriano Menino de Macêdo Júnior

Centro Universitário Natalense, Brasil

http://lattes.cnpq.br/4134152465913204

http://orcid.org/0000-0001-6367-1088

adrianomenino2016@gmail.com

Clécio Danilo Dias da Silva (iD)

Universidade Federal do Rio Grande do Norte, Brasil

http://lattes.cnpq.br/4235157508528733

http://orcid.org/0000-0002-7776-8830

adrianomenino2016@gmail.com

Swianny Rodrigues de Oliveira (iD

Universidade Federal do Rio Grande do Norte, Brasil

http://orcid.org/0000-0002-5297-139X

adrianomenino2016@gmail.com

\author{
Shuliete Duarte da Silva (iD) \\ Faculdade Venda Nova do Imigrante, Brasil \\ http://lattes.cnpq.br/6186232992315867 \\ http://orcid.org/0000-0002-5957-2519 \\ adrianomenino2016@gmail.com \\ Rafael Araújo da Silva (iD \\ Universidade Federal do Rio Grande do Norte, Brasil \\ http://lattes.cnpq.br/3961915577665374 \\ http://orcid org/0000-0001-7695-7827 \\ adrianomenino2016@gmail.com
}

d

DOI: 10.6008/CBPC2318-3047.2021.002.0009
Referencing this:

MACÊDO JUNIOR, A. M.; SILVA, C. D. D.; OLIVEIRA, S. R.; SILVA, J. D.; SILVA, R. A.. Recursos fílmicos e a prática pedagógica: um estudo sobre a visão de licenciandos sobre a sua utilização na educação básica. Educationis, v.9, n.2, p.70-78, 2021. DOI: http://doi.org/10.6008/CBPC2318-3047.2021.002.0009 


\section{INTRODUÇÃO}

O cinema se tornou uma paixão por grande parte da população mundial. É através dos filmes que as pessoas podem ter um maior entendimento do mundo que os cercam, bem como, entender pontos de vista diferentes acerca de uma determinada temática, refletindo sobre as ideias que são transmitidas (PEREIRA et al., 2018b). Atualmente o público mais cativado pelos filmes é a dos jovens. É dentro deste contexto que este recurso midiático se torna peça chave como recurso didático para os professores utilizarem no contexto da sala de aula.

A didática fílmica vem como um suporte fundamental a prática educativa, pois oferece embasamento para dinamização do processo ensino-aprendizagem. No sistema educativo o docente deve variar e flexibilizar suas metodologias a partir da necessidade de sua turma de alunados. Os saberes didáticos oferecem ao professor diferentes formas de ensinar e de compreender a construção do conhecimento com a aplicação de múltiplas metodologias que colabore para a concretização dos seus objetivos. De acordo com Cunha (2004) os docentes devem se reinventar nas salas de aulas, assim:

(...) Pressupõem a condição do professor de ser o artífice, junto com seus alunos, de estratégias que favoreçam uma aprendizagem significativa, ou seja, que ancore nas estruturas culturais, afetivas e cognitivas dos estudantes as novas aprendizagens. Envolve a seleção de técnicas e procedimentos de ensino, bem como a seleção de recursos apropriados. Envolve a condição de protagonismo necessário ao exercício intelectual do professor e seus alunos. (CUNHA, 2004)

Muitas disciplinas da educação básica podem ter bastante êxito usando filmes em sua didática, como obter "imaginário científico, representações da ciência e dos cientistas, aspectos da história e da natureza da ciência, entre outros" (PEREIRA et al., 2018b). Entretanto, ao utilizar esse recurso devem ser tomados alguns cuidados. Segundo Pereira et al. (2018):

(...) Entretanto, outras questões precisam ser consideradas quando se planeja utilizar filme como estratégia didática. Os longos metragens podem trazer valores que são contraditórios aos que queremos trabalhar, seja de forma velada, como por exemplo, supervalorização do consumo, padrões de beleza, visões estereotipadas e espetacularizadas das ciências, ou de forma mais explícita, como violência, vingança, entre outros. (PEREIRA et al., 2018)

Cada vez mais o professor tem sido desafiado em prender a atenção dos seus alunos, muitas das vezes faltam mesmo uma inovação em sua metodologia de ensino e aprendizagem, fazendo com que os alunos não interajam nas aulas e até mesmo perdendo o interesse na disciplina. Dependendo da disciplina até mesmo maioria delas, podem não ser bem interpretada pelos discentes. Aderir a uma metodologia fílmica pode muitas vezes ajudar a interação aluno X professor, o filme em sua essência pode passar para os alunos contextos menos complexos e uma estratégia de exemplos maiores, associados à realidade cotidiana, saindo da rotina da linguagem coloquial do docente e de outros materiais didáticos escritos, como os livros (FARIA et al., 2019; MACEDO JÚNIOR et al., 2021).

Para alcançar a atenção dos alunos de ensino fundamental e médio, e manter um canal interativo é necessário se reinventar com relação às novas práticas pedagógicas, sabemos que a tecnologia pode favorecer em diversos fatores, hoje a internet está a um alcance maior das instituições de ensino, favorecendo a aplicação didática de filmes, que tem som, imagem, ajudando no processo de ensino- 
aprendizagem do aluno (FARIA et al., 2019; MACEDO JÚNIOR et al., 2021). Então para Bridi et al. (2012) os usos dos filmes contribuem para a educação de alunos:

[...] O uso do cinema é capaz de facilitar o diálogo de professores com alunos, de alunos com alunos e de os alunos consigo mesmo. Este estimula o debate e o relacionamento interpessoal, que são elementos importantes para a formação do sujeito, pois por intermédio da leitura e análise de imagens, os temas tratados e retratados na obra fílmica podem desencadear importantes reflexões para a construção de conhecimento. (BRIDI et al., 2012)

No que tange à globalização e a era digital e tecnológica, que cada vez mais avança, as escolas não podem se abster em adquirir novas estratégias didáticas pedagógicas, ficar para traz nesse contexto é perder o aluno das salas e aula, este vai se interessar cada vez menos nos conhecimentos e tudo que se aplica na escola. E mesmo que a instituição não possua internet, ela ainda pode fazer uso do recurso do DVD para reproduzir filmes, ou seja, muitas maneiras que requerem poucos recursos financeiros podem ser utilizadas (FARIA et al., 2019; MACEDO JÚNIOR et al., 2021). Para Bridi et al. (2012) o repertório que os longasmetragens trazem é muito importante, pois:

[...] múltiplas linguagens implícitas na educação através do cinema, os longas-metragens trazem inúmeros conhecimentos, pois além de relatar uma história, eles são capazes de estimular cada receptor/espectador a perceber uma ideia, através da narração, da trilha sonora, da imagem, dentre outras formas de expressão. (BRIDI et al., 2012)

Os recursos audiovisuais, como os filmes, abrem caminhos para o diálogo, o compartilhamento de conhecimentos, ideias, questionamentos e reflexões. Os debates e discussões sobre diversas temáticas sociais realizadas em sala de aula oportunizam aos educandos a construção do conhecimento de forma significativa e o desenvolvimento de uma consciência crítica perante a sociedade e ao contexto que estão inseridos.

Este estudo tem como objetivo discutir sobre a importância da utilização de filmes em sala de aula e como esse recurso pedagógico, aplicado de maneira correta e coerente pelo professor, pode despertar no aluno o interesse pelo conhecimento. E apresentar dados em relação ao olhar dos discentes da graduação, acerca da utilização dessa ferramenta em sala de aula.

\section{MATERIAIS E MÉTODOS}

O presente trabalho tratou-se de um estudo com abordagem quantitativa e qualitativa de natureza aplicada, com procedimentos de campo, com objetivo descritivo (PEREIRA et al., 2018a). Desenvolvida durante $\circ$ 1ำ período da graduação do curso de Letras Língua portuguesa da UERN - Universidade Estadual do Rio Grande do Norte.

As redes sócias podem ajudar os pesquisadores na coleta de dados quantitativos através de questionários, as informações são coletadas em tempo real, o que favorece que independentemente do local onde quer que esteja seu objetivo possa ser alcançado (FREITAS et al., 2020; COUTO et al., 2020; CARVALHO et al., 2020).

Esse estudo foi realizado na Região Nordeste do Brasil, Estado de Mossoró - RN, na UERN Universidade Estadual do Rio Grande do Norte (Mapa 1), com a turma do 1o período dos discentes do curso 
de Letras - língua Portuguesa. Essa turma é composta por 20 alunos, porém o pesquisador principal deste trabalho não foi incluso, sendo assim os 19 participantes responderam ao questionário. Assim foi aplicado um questionário compondo sete perguntas, disponível na plataforma Google Forms, criadas pelos pesquisadores envolvidos, que visa saber dos participantes se eles utilizarão filmes como ferramenta metodológica no processo de ensino-aprendizagem de alunos.

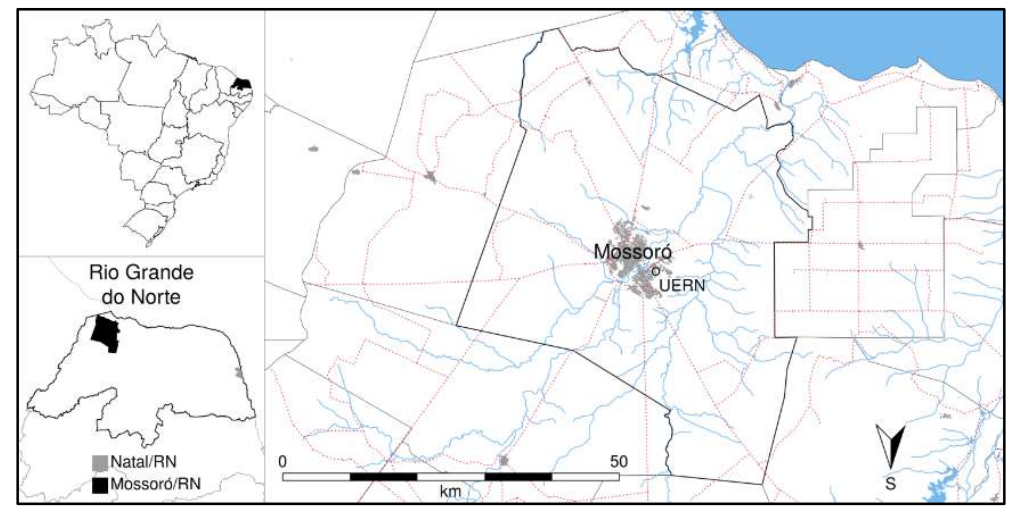

Mapa 1: Localização da UERN - Universidade Estadual do Rio Grande do Norte. Avenida Prof. Antônio Campos - Pres. Costa e Silva, Mossoró - RN, Cep: 59610-210.

Os dados obtidos nesta pesquisa foram processados e tornaram-se resultados principal do trabalho, a ferramenta escolhida para a elaboração e aplicação das perguntas foi o Google Forms ${ }^{1}$. O veículo para a aplicação do questionário foi por meio de mídia social, sendo esta através do WhatsApp. O TCLE - Termo de consentimento Livre e Esclarecido foi colhido antes do questionário ser iniciado.

Este estudo envolveu apenas opinião sobre a didática fílmica como metodologia em salas de aulas mantendo os dados dos participantes é totalmente anônimo o que justifica a ausência da apreciação de um Comitê de Ética, em conformidade com a Resolução no 510/2016, em que não é necessário registrar no Comitê de Ética e Pesquisa com seres humanos aqueles estudos que utilizam dados de acesso público, domínio público e/ou que estejam em banco de dados sem possibilidade de identificação individual.

\section{RESULTADOS E DISCUSSÃO}

Todos os discentes do curso de Letras Língua Portuguesa concordaram em responder questionário, dos 19 participantes $79 \%(n=15)$ são do sexo feminino enquanto que o sexo masculino corresponde a $21 \%$ ( $n=4)$. Dados disponíveis no gráfico 1.

Independentemente de qualquer gênero sexual, o futuro docente já deve ter em mente que ensinar é uma arte, transferir o conhecimento não é o bastante, mas fazer com que os alunos interpretem e absorvam seus ensinamentos é o dever do professor. Sendo assim Viglus (2009) em corrobora para esta pesquisa no que tange aos 22 professores, da disciplina de história, entrevistados todos alegaram achar importante o uso do filme em sala de aula, afirmando que "o mesmo pode auxiliar a elucidar fatos que o professor muitas vezes deixa de comentar e também levar o aluno a fazer uma reflexão da história através da fonte cinematográfica" (VIGLUS, 2009). Os filmes escolhidos pelos docentes têm total relevância a sua

${ }^{1}$ https://docs.google.com/forms/d/e/1FAlpQLSdPA2a9emc193XQtwV7iKnfrgvgyT97VeOs4H-BrF3IPAl-qQ/viewform?usp=sf_link 
disciplina, pois a, "contribuição que o filme poderá acrescentar na construção do conhecimento do aluno sobre aquela temática analisada em sala de aula" (VIGLUS, 2009).

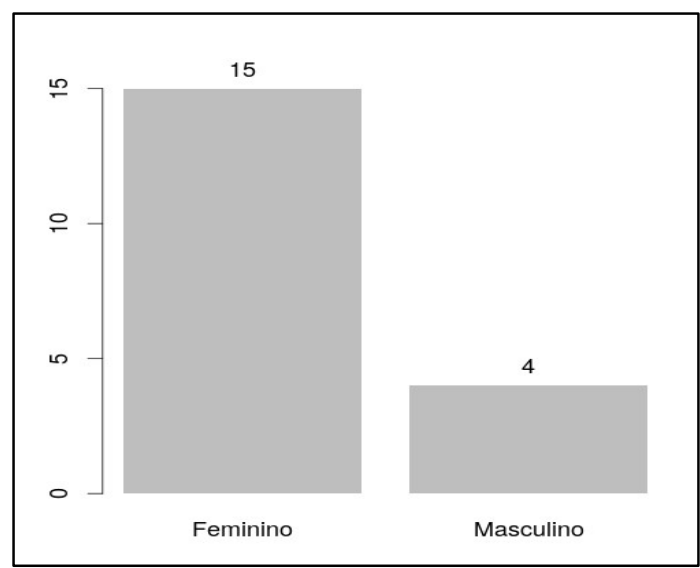

Gráfico 1: Variável dos discentes do curso de letras segundo seu sexo.

A turma de Letras Língua Portuguesa apresentou-se bem heterogênea em relação ao gosto por gêneros de filmes. Do total de participantes $32 \%(n=6)$ tem gosto pelo gênero do romance, $16 \%(n=3)$ preferem o gênero da ficção científica e $10 \%(n=2)$ optaram pelo gênero de ação. Um grupo de nove estudantes apontaram outros gêneros, diferente dos outros colegas (42\%), como por exemplo, suspense, terror, comédia, documentários, etc. forma diferente. Dados disponíveis no gráfico 2.

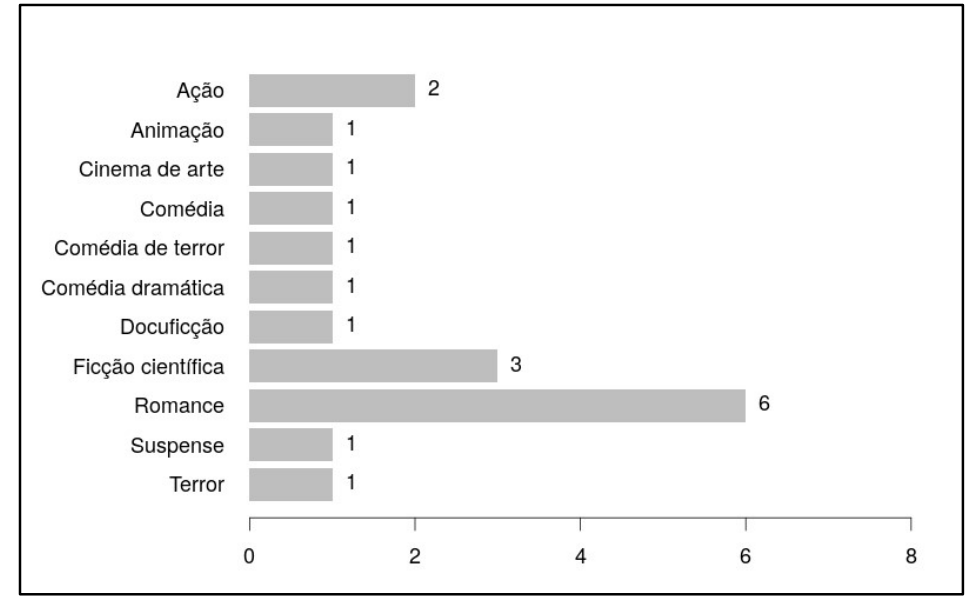

Gráfico 2: Variável dos discentes do curso de letras segundo o gênero de filmes escolhido.

De acordo com Mendonça et al. (2008) o uso da tecnologia tele projetada é capaz de transferir para as pessoas o conhecimento e a representação de uma grande e nova variedade de "sistemas símbolos", captadas pelas funções mentais, ou "processo cognitivo", do ser humano, como eles vão adquirir as funções de percepção, aprendizagem, raciocínio entre outros. Assim os filmes atribuem para os alunos de qualquer grau de escolaridade o aprendizado por meio do método "vicário", ou seja, através da observação de experiências ilustradas nas telas. $O$ estudo de Mendonça et al. (2008) também afirma que o processo ensinoaprendizagem ocorre durante a apreciação de qualquer filme, o conhecimento pode ser transferido e extrapolado, uma vez que o aluno enquanto expectador, "não são simplesmente observadores passivos das imagens em uma tela; eles podem ter muitas e diferentes respostas, as quais, frequentemente, tornam-se uma parte essencial da experiência do filme" (MENDONÇA et al., 2008). Os filmes são observados pelos 
telespectadores, que vão formular um ponto de vista, seja a obra "reflexos da realidade ou artefatos culturais", os filmes são compostos por realidades das vidas sociais e sua organização, podendo aparecer de forma destorcida, alteradas ou até mesmo na forma como ela realmente é (MENDONÇA et al., 2008).

Como dito desde a introdução desta pesquisa, o professor pode e deve-se munir das inúmeras formas de metodologias de ensino-aprendizagem, nos dias atuais com a globalização da internet, muitos lugares no mundo que eram inacessíveis, hoje dispõem de internet de boa qualidade, a plataforma streaming nunca foi tão fácil de ser possuída por toda a população, ela comporta uma grande variedade de filmes de todos os gêneros possíveis para se assistir. "À linguagem cinematográfica oferece a vantagem de conseguir demonstrar com clareza uma situação ou o transcorrer de uma ação, além de impacto emotivo" (BARBOSA et al., 2007, citado por MENDONÇA et al., 2008). Muitas disciplinas de ensino podem ser impactadas pela metodologia didática de ensino-aprendizagem dos filmes, esse tipo de material de ensino garante que os telespectadores possam ter uma maior interação da mensagem que filme passa, podendo captar a linguagem corporal dos atores, facilitando a interpretação da obra criada pelo diretor cineasta, esses sentimentos somente são perceptíveis através de filmes (MENDONÇA et al., 2008).

Dos futuros professores formados no curso de Letras Língua Portuguesa, apenas 95\% ( $n=18)$ pretendem ao termino do seu curso utilizarem a didática fílmica, enquanto que apenas $5 \%(n=1)$ disseram não se interessar nesse tipo de metodologia de ensino-aprendizagem. Dados disponíveis no gráfico 3.

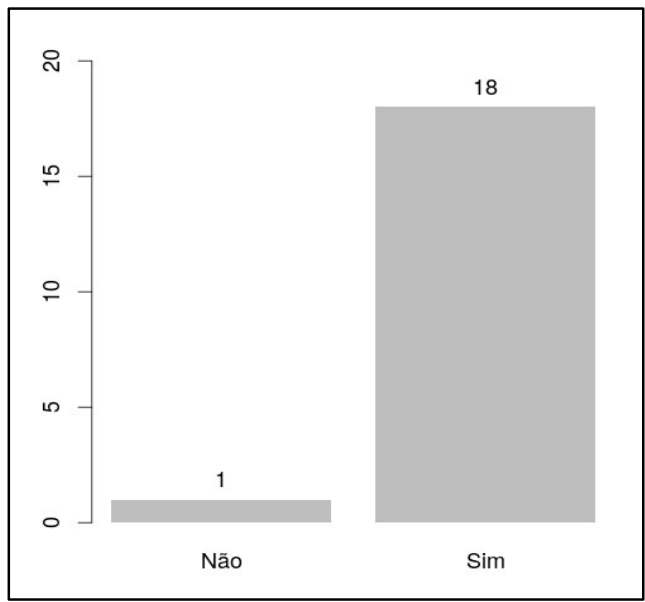

Gráfico 3: Variável dos discentes do curso de letras segundo a pretensão ou não de usar filmes na didática de ensino.

O modo interação Professor $X$ aluno deve ser estimulo desde o início do ano letivo até seu termino. Segundo Rodrigues et al. (2017) as instituições de ensino vêm se adaptando cada vez mais para incluir o cinema como ferramenta pedagógica. Os filmes são capazes de aproximar os estudantes com culturas "cotidianas e elevadas" podendo o filme ser uma obra de arte completa, composta de "pois o cinema é o campo no qual a estética, o lazer, a ideologia e os valores sociais mais amplos". Recursos audiovisuais ampliam a didática do professor em sala de aula, este deve utilizar-se de filmes que se encaixem na temática da sua disciplina ministrada, a fim de canalizar discussões em sala de aula sem se perder o objetivo do seu ensinamento. Estudantes do ensino médio podem ser comtemplados com o uso de filmes nacionais em salas de aulas, o professor aplica de forma "coerente e consciente" a obra, e os estudantes serão capazes de captar 
fatos "históricos e culturais" da história do Brasil, perdidos ao longo dos anos (RODRIGUES et al., 2017).

Os aspectos visuais dos filmes podem ajudar na interpretação, de certo conteúdo, de certa disciplina, no enunciado do filme pelos jovens estudantes. De acordo com o Estudo de Nascimento (2017) o pesquisador elaborou um projeto que foi aplicado nas "turmas de 3ㅜ, 4o e 5o anos do Ensino Fundamental do Núcleo de Educação da Infância” e na "Escola Estadual General Antônio V. Santos Rocha que atende o público de 1o ao 5o ano do Ensino Fundamental". Seu projeto se se chama "CINEICLUBE" sua proposta é rodar filmes na sala de aula, estes escolhidos pelas crianças, que "apreciaram a obra e depois realizaram o debate sobre as questões que mais Ihe chamaram a atenção sobre o filme, apontando o que sentiram, os aspectos que mais Ihe emocionaram, o que as mensagens do filme geraram para cada um", ao termino da sessão de filmes, os professores iniciam uma roda de conversas, na qual, as "As crianças são convidadas a participar, compartilhar seus diferentes olhares", após o debate os alunos são convidados a "redigirem uma síntese sobre o filme, que será utilizada na divulgação da sessão" (NASCIMENTO, 2017). O autor Nascimento (2017) concluiu em sua obra que os alunos do ensino fundamental adquiriram uma nova forma de ver a realidade, compreendendo o texto o filme como um método de reflexão, favorecendo melhor aprendizado.

Quando os graduandos foram questionados sobre o potencial do uso dos filmes para o processo de ensino-aprendizagem dos estudantes da educação básica, todos responderam que sim, $100 \%(n=19)$. Alguns relatos dos estudantes podem ser vistos a seguir: Resposta do aluno 1: 'Extremamente importante, muitos assuntos são importantes ver uma vivência, mesmo que seja cenográfica, fica mais próximo da realidade'; Resposta do aluno 16: 'Os filmes em sala de aula trazem uma dinâmica diferente para os alunos saírem mais do comodismo e aulas monótonas. Vai facilitar os estudantes a terem um interesse maior para estudar, por exemplo, se usamos o filme através dele podemos fazer os alunos criarem um resumo sobre o filme e a opinião sobre. Vai ajudar o aluno a melhorar a escrita e interpretar o que a história do filme quis passar'; Resposta do aluno 17: 'Acho que o potencial é muito grande e é um mundo que os jovens de hoje em dia vivem, filmes, séries e isso faria com que os alunos da educação básica ou até mesmo universitários tenham um bom desenvolvimento nas aulas'; Resposta do aluno 19: 'Os alunos podem aprender de uma forma fácil, leve e divertida, seja uma lição moral do filme ou algo sobre alguma matéria específica'.

Consoante Ramos (2018) destaca em sua obra a importância da Literatura e Cinema estarem entrelaçadas no processo ensino-aprendizagem. Em sala de aula o professor pode ser valer de obras literárias que viraram filmes para ampliar a discussão. $\mathrm{O}$ autor aborda em seu trabalho algumas obras que possam ser usadas em sala de aula, como por exemplo, "História sem fim (1984) de Wolfgang Petersen, adaptação de livro de Michael Ende; Sociedade dos poetas mortos (1989) de Peter Weir; Cyrano de Bergerac (1990) de Jean-Paul Rappeneau, da peça de Edmond Rostand" (RAMOS, 2018).

Ramos (2018) alega que o cinema em sala de aula pode mudar o comportamento dos estudantes, pois dentre os filmes exibidos um que provocava interesse em ser copiado pelos alunos seria "Sociedade dos poetas mortos" que demonstra "Todd Anderson, Neil Perry e Knox Overst, cujos personagens cultuam poesia estimulados que foram pelo professor de Literatura John Keating, em grande interpretação de Robin 
Williams" (RAMOS, 2018). Das demais reações desencadeadas eram de se esperar o seguinte desejo:

Que [...] os alunos quiserem ter um professor de literatura como Keating. Por outro lado, muitos docentes certamente gostariam que seus alunos assumissem um compromisso com a educação voltada ao culto das artes e de que pudessem ser recebidos com a célebre saudação: "Oh, Captain! My Captain!". São cenas que marcam o espírito de um mestre. (RAMOS, 2018)

Outra das demais produções eleitas por Ramos (2018), podemos destacar "Encontrando Forrester (2000), de Gus Van Sante, com roteiro de Mike Rich e produção de Sean Connery. William Forrester (Sean Connery), professor". O filme conta a história de um docente e autor recolhido, que observa os predicativos de "Jamal Wallace (Robert Brown), adolescente negro norte-americano vindo de um colégio do bairro pobre Bronx". Em virtude de seu ótimo histórico e seu desempenho nos testes aplicados em sua escola, frequentada anteriormente, o adolescente é beneficiado com uma bolsa para estudar em uma escola de alto conceito em Manhattan. Jamal logo demonstra que não só tem talento para o basquete, mas, que domina a arte da escrita, onde se estabelece uma relação recíproca entre os dois. "Mais tarde o professor termina por receber lições de vida do ex-aluno" (RAMOS, 2018).

Para Ramos (2018) os filmes podem não só transferir conhecimentos diversos para alunos, pois os filmes podem abordar inúmeras temáticas, mas servem também para incentivar a aproximação dos alunos e do professor na sala de aula.

\section{CONCLUSÕES}

Dos métodos de ensino-aprendizagem mais utilizados pelos professores, a imagem é a que mais se sobressai no que tange a formação do indivíduo, dessa forma introduzir a tecnologia na sala de aula pode facilitar e agradar os estudantes, captando cada vez mais a sua atenção. O hábito de assistir a um longametragem com base em uma disciplina teórica pode alavancar o conhecimento dos discentes, criando neles um ponto de vista crítico e consciente da realidade do mundo.

O papel do filme da vida do aluno é de suma importância, para a construção do saber de cada indivíduo. Este trabalho aponta para que desde a graduação de alunos do curso de Letras Língua Portuguesa, o filme já é pretensão como objeto estratégico metodológico nas futuras aulas dos futuros docentes. O filme como recurso de ensino-aprendizagem é uma forma ímpar de torna matérias muitas teóricas em práticas, a importância da formação continua dos docentes, bem como, a busca por sempre se manter atualizado em um universo prático pedagógico, é de vital importância. Em pleno século XXI os meios audiovisuais já se tornam um marco alcançado dentro dos milhares salas de aulas no Brasil, ficando de responsabilidade dos professores utilizarem esses recursos com muita engenhosidade, para instigar e atrair os alunos, tornandoos sujeitos históricos.

\section{REFERÊNCIAS}

BARBOSA, A. R.; TEIXEIRA, L. R.. A utilização de filmes no ensino de administração. In: ENCONTRO DE ENSINO E PESQUISA EM ADMINISTRAÇÃO E CONTABILIDADE, ENEPQ, 1. Anais. Recife, 2007.
BRIDI, J. P. M.; CAMARGO, M. A. S.; SILVA, V. M.. A linguagem fílmica enquanto importante instrumento desencadeador de reflexões interdisciplinares. In: INTERCOM - SOCIEDADE BRASILEIRA DE ESTUDOS INTERDISCIPLINARES DA COMUNICAÇÃO; CONGRESSO DE 
CIÊNCIAS DA COMUNICAÇÃO NA REGIÃO SUL, 18. Anais. Chapecó, 2012.

CARVALHO, M. S.; LIMA, L. D. D.; COELI, C. M.. Ciencia en tiempos de pandemia. 2020.

COUTO, E. S.; COUTO, E. S.; CRUZ, I. D. M. P.. Fique em casa: educação na pandemia da covid-19. Interfaces CientíficasEducação, v.8, n.3, p.200-217, 2020. DOI: http://doi.org/10.17564/2316-3828.2020v8n3p200-217

CUNHA, M. I.. A docência como ação complexa: o papel da didática na formação de professores. Champagnat, 2004.

FARIA, M. E. A.; ALVES, D. A.. As potencialidades da linguagem fílmica no ensino de geografia física: uma sequência didática a partir do filme abril despedaçado. Para Onde!?, v.12, n.2, p.155-163, 2019. DOI: http://doi.org/10.22456/1982-0003.97518

FREITAS, A. M.; BIRCKOLZ, C. J.. Utilização das redes sociais digitais pelos alunos de um polo de educação a distância. Diálogos Interdisciplinares, v.9, n.3, p.39-52, 2020.

MACEDO JÚNIOR, A. M.; OLIVEIRA, S. R.; SILVA, C. D. D.; SANTOS, E. A.; SILVA, J. D.; SANTOS, M. C.. Educational profile of the illiterate population in Rio Grande do Norte in 2010. Research, Society and Development, v.10, n.3, p.e56010313877, 2021. DOI: http://doi.org/10.33448/rsdv10i3.13877
MENDONÇA, J. R. C.; GUIMARÃES, F. P.. Do quadro aos "quadros": o uso de filmes como recurso didático no ensino de administração. Cadernos EBAPE, v.6, p.01-21, 2008. DOI: http://doi.org/10.1590/S1679-39512008000500003

NASCIMENTO, L. V.. Cineiclube: uma proposta para o cinema na educação da infância. In: COPRECIS - CONGRESSO NACIONAL DE PRÁTICAS EDUCATIVAS. Anais. 2017.

PEREIRA, A. S.; SHITSUKA, D. M.; PARREIRA, F. J.; SHITSUKA, R.. Metodologia da pesquisa científica. Santa Maria: UFSM, 2018a.

PEREIRA, B. F. M.; SÁ, E. F.; FONSECA, M. A.. Uso de recursos fílmicos como estratégia didática por professores da educação básica. Revista Interdisciplinar Sulear, v.1, n.1, 2018b.

RAMOS, I.. Literatura, cinema e sala de aula/literatura, cine y clase. Revista ECOS, v.25, n.2, 2018.

RODRIGUES, W.; BARROS, C. A.. Cinema e identidade cultural brasileira: possíveis reflexões para uso de filmes em sala de aula. Arteriais-Revista do Programa de Pós-graduação em Artes, v.3, n.4, p.76-83, 2017. DOI: http://dx.doi.org/10.18542/arteriais.v3i4.4866

VIGLUS, D.. O filme na sala de aula: um aprendizado prazeroso. Rede Estadual de Ensino do Estado do Paraná do Programa de Desenvolvimento Educacional (PDE), 2009.

A CBPC - Companhia Brasileira de Produção Científica (CNPJ: 11.221.422/0001-03) detém os direitos materiais desta publicação. Os direitos referem-se à publicação do trabalho em qualquer parte do mundo, incluindo os direitos às renovaç̃ões, expansões e disseminações da contribuiç̃o, bem como outros direitos subsidiários. Todos os trabalhos publicados eletronicamente poderão posteriormente ser publicados em coletâneas impressas sob coordenação da Sustenere Publishing, da Companhia Brasileira de Produção Científica e seus parceiros autorizados. Os (as) autores (as) preservam os direitos autorais, mas não têm permissão para a publicação da contribuição em outro meio, impresso ou digital, em português ou em tradução. 